\title{
OPTIMIZATION OF NEUROTRANSMITTERS SEPARATION UNDER HILIC CONDITIONS
}

\author{
RALUCA TAMPU ${ }^{*}$, CATALIN TAMPU ${ }^{1}$ \\ I "Vasile Alecsandri" University of Bacau, Calea Marasesti 157, Bacau, 600115, Romania
}

\begin{abstract}
This paper presents the optimization of a hydrophilic interaction chromatographic method for the separation of eleven catecholamines, indolamines and their precursors and metabolites. The studied parameters are: the organic modifier nature and percentage, the salt nature and concentration, the mobile phase $\mathrm{pH}$ and the column temperature. The best results in terms of separation were obtained using a mobile phase composed of acetonitrile and ammonium formate $(150 \mathrm{mM} \mathrm{pH} 3) 85: 15 \mathrm{v}: \mathrm{v}$.
\end{abstract}

Keywords: catecholamines, HILIC, neurotransmitters

\section{INTRODUCTION}

In the nervous system, neurotransmitters are the most common class of chemical messengers. Neurotransmitters can be divided into: small amino acids and biogenic amines [1]. Catecholamines (dopamine, norepinephrine and adrenaline) (Table 1) are neurotransmitters of the monoamine family which are synthesized from the same amino acid (tyrosine) and therefore have a similar structure consisting of an aromatic nucleus with two hydroxyl groups (the catechol nucleus) and an ethylamine as side chain [2].

Serotonin (S) belongs to the family of indole-type neurotransmitters. It is synthesized from tryptophan (TRP). S is the neurotransmitter for which has the largest number of receivers.

Catecholamines and indolamines, as well as their metabolites, are polar and non-volatile molecules. These are substances that are very sensitive to light, oxygen, temperature and $\mathrm{pH}$. That is why they must be kept in an acid medium ( $\mathrm{pH}$ less than 3), protected from light and at a low temperature. Miki and Sudo [3] carried out a study showing the effect of $\mathrm{pH}$, storage time and temperature on the stability of catecholamines (DA, A and NA) in urine. They were able to observe that at a $\mathrm{pH} \leq 7$, the urine kept at less than $4{ }^{\circ} \mathrm{C}$ do not lose significant amounts of catecholamines for at least the first 7 days, while at $\mathrm{pH} 10$ they degrade rapidly even at $-20{ }^{\circ} \mathrm{C}$. This study highlights the importance of temperature on the conservation of catecholamines.

In the human body, catecholamines and indolamines, as well as their metabolites, proved to be markers in the diagnosis of different diseases, like: Alzheimer's disease, Parkinson's disease, pheochromocytoma or neuroblastoma [4-7].

Because of the low physiologic concentrations of these compounds and the tendency of the catechol group to be easily oxidized, quantification of catecholamines presents numerous difficulties.

\footnotetext{
* Corresponding author, email: tampu.raluca@ub.ro

(C) 2017 Alma Mater Publishing House
} 
Although reversed phase chromatography (RPLC) is the most currently used method for the analysis of catecholamines and related compounds [8-13], recently hydrophilic interaction liquid chromatography (HILIC) began as an alternative for the separation of neurotransmitters [6, 14-16]. In HILIC, the stationary phases are polar and the mobile phases are composed of water and an important amount (60-98\%) of organic solvent, leading to the elution of the analytes in their increasing polarity order [17-20].

Table 1. Structure of the target compounds.

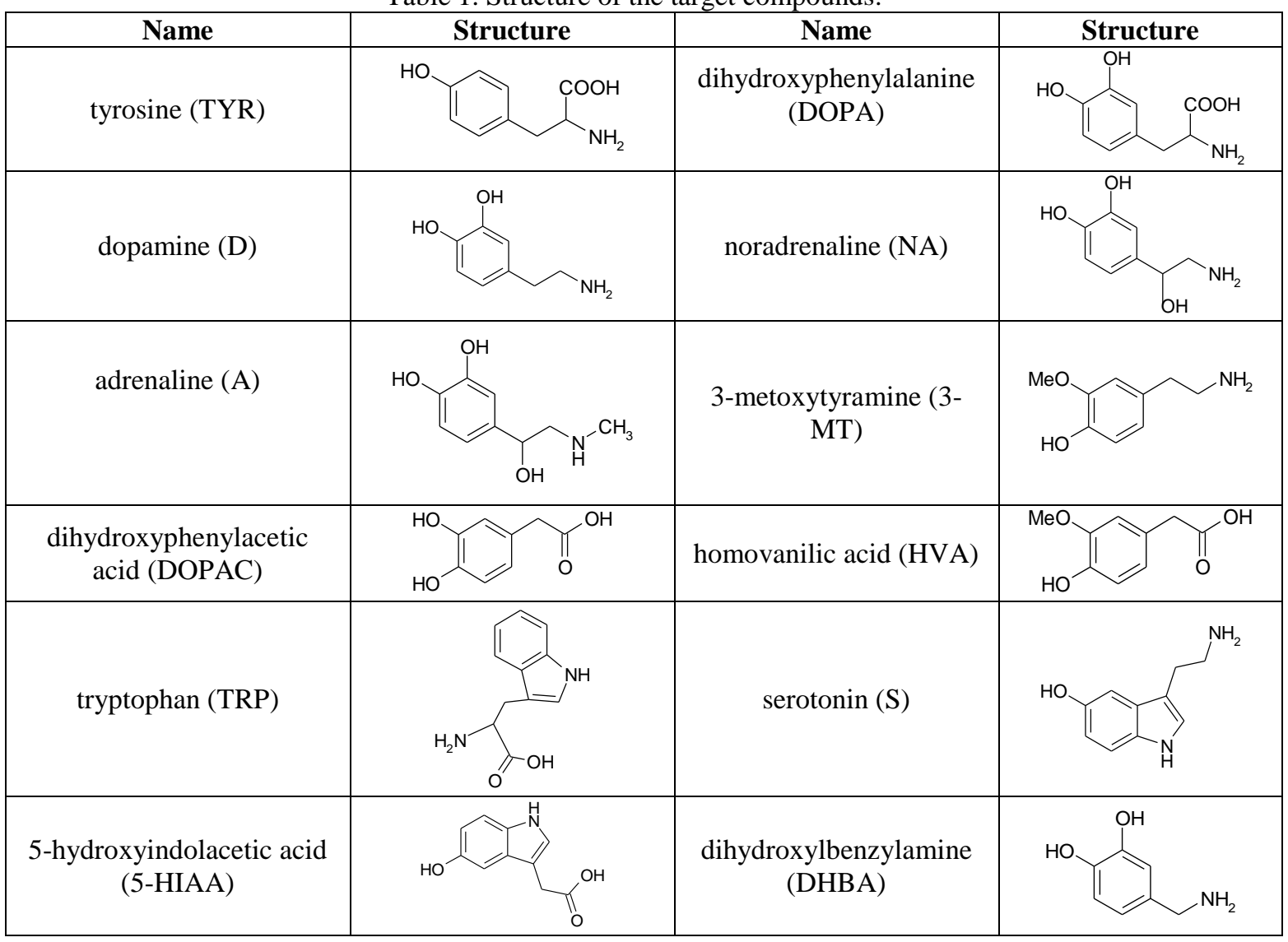

The aim of this study was to optimize a HILIC method for the separation of 11 catecholamines, indolamines, and their metabolites and precursors (dopamine, norepinephrine, adrenaline, serotonin, 5-hydroxyindolacetic acid, dihydroxyphenylacetic acid, homovanilic acid, 3-metoxytyramine, tryptophan, dihydroxyphenylalanine and tyrosine) that could be coupled to mass spectrometric (MS) detection for the quantification of the target compounds in biological matrixes. In order to be able to do that, a highly volatile mobile phase with a reasonable amount of salt is need to insure the lowest MS detection limits.

\section{EXPERIMENTAL SETUP}

The optimization of the chromatographic separation was carried out using an Agilent 1100 series (Waldbronn, Germany) system with: pump, auto sampler with $5 \mu \mathrm{L}$ loop, column oven and UV-diode array detector (the set wave length was $280 \mathrm{~nm}$ ). The column was kept at $20^{\circ} \mathrm{C}$ for all the experiments with the exception of the study of the temperature influence were it was varied between 20 and $40{ }^{\circ} \mathrm{C}$. Chemstation software version A.08.03 (Waters) was used for the chromatographic data handling. All the analysis were realized using bear silica column Silica Uptisphere Strategy 100A 5 $\mu \mathrm{m}$ HIS, L x $\Phi=250$ x $2.0 \mathrm{~mm}, 5 \mu \mathrm{m}$ (Interchim, France).

All the chemicals and reagents were of analytical grade and were purchased as follows:

- $\quad$ A, DOPAC, DA, DOP0A, HVA, 5-HAIA, 3-MT, NA, S, TRP and TYR from Sigma-Aldrich (StQuentin Fallavier, France);

- $\quad 3,4$ dihydroxybenzylalanine (DHBA - internal standard), ammonium formate $\left(\mathrm{HCOONH}_{4}\right)$ and acetate $\left(\mathrm{CH}_{3} \mathrm{COONH}_{4}\right)$, formic $(\mathrm{HCOOH})$ and acetic acids $\left(\mathrm{CH}_{3} \mathrm{COOH}\right)$ from Fluka (St.-Quentin-Fallavier, France); 
- $\quad$ perchloric acid $\left(\mathrm{HClO}_{4}\right)$ from VWR Prolabo (Darmstadt, Germany);

- $\quad$ acetonitrile $(\mathrm{ACN})$ and methanol $(\mathrm{MeOH})$ from J.T. Baker (Noisy le Sec, France).

The analytes and mobile phase solution were prepared using purified water, produced by the Elgastat UHQ II system (Elga, Antony, France).

For each of the 12 compounds stock standard solutions of $1000 \mu \mathrm{g} \cdot \mathrm{mL}^{-1}$ were prepared dissolving the appropriate weighted amounts in $\mathrm{HClO}_{4}\left(0.2 \mathrm{~mol} \cdot \mathrm{L}^{-1}\right)$, that were stored at $-80{ }^{\circ} \mathrm{C}$. The solutions injected in the chromatographic system were prepared by diluting the stock solutions mixtures of buffer and ACN in order to have an injection solvent as close as possible to the mobile phase. The injection solvent composition plays an important role in HILIC [21].

\section{RESULTS AND DISCUSSION}

The influence of different chromatographic parameters, such as: organic modifier nature and percentage, salt nature and concentration, column temperature and mobile phase $\mathrm{pH}$, on separation of the target compounds was studied.

For this study we have selected dihydroxylbenzylamine (DHBA) as internal standard. Due to the high $\mathrm{pH}$ sensitivity of the catecholamines, the mobile phase $\mathrm{pH}$ was kept at 3 . Under these conditions our analytes are bearing different charges as follows [15]:

- $\quad$ DA, NA, A, S, 3-MT and DHBA (biogenic amines) are protonated and thus, positively charged;

- DOPA, TYR and TRP (amino acids) have the carboxylic functions deprotonated and the amine functions protonated resulting in zwitterionic compounds that have the global charge zero;

- $\quad$ DOPAC, HVA and 5-HIAA (carboxylic acids) having the pKa values of 3.6, 3.9 and 4.2, respectively, are most probably partially dissociated and thus, partially negatively charged.

\subsection{Influence of the organic modifier type and percentage content of in the mobile phase}

As expected in the HILIC mode the increase of the organic modifier ( $\mathrm{ACN}$ ) percentage in the mobile phase lead to the augmentation of the retention factor $(\mathrm{k})$ of most of the target compounds. For example, for TYR the retention factor doubled when the ACN percentage increased from 70 to $80 \%$, further increase to $90 \%$ led to a 12 times increase of the $\mathrm{k}$ value. On the other hand, no significant modifications of the retention factor of the acidic compounds (DOPAC, HVA, 5-HIAA) (Figure 1).

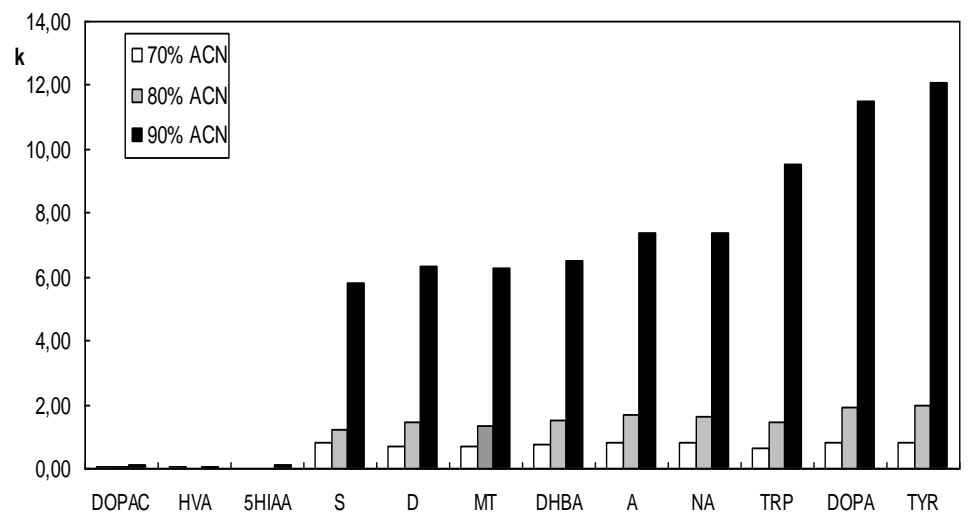

Fig. 1. Variations of the retention factors for analytes with the ACN percentage.

The replacement of $\mathrm{ACN}$ with $\mathrm{MeOH}$ lead to the decrease of the retention coefficients of all the compounds and thus to their insufficient separation (data not shown). Under these conditions for the following experiments ACN was used as organic modifier.

\subsection{Influence of the salt nature and concentration on the retention factor}

For the influence of the salt concentration on the retention of the analyses, $\mathrm{HCOOH}_{4}$ concentration in the aqueous phase was varied between 20 and $150 \mathrm{mM}$. That led to an overall concentration of alt in the mobile 
phase that was comprised between 3 and $22.5 \mathrm{mM}$. The retention increased only for the two amino acids, TYR and DOPA, for the rest of the compounds the salt concentration did not have a significant influence (Figure 2).

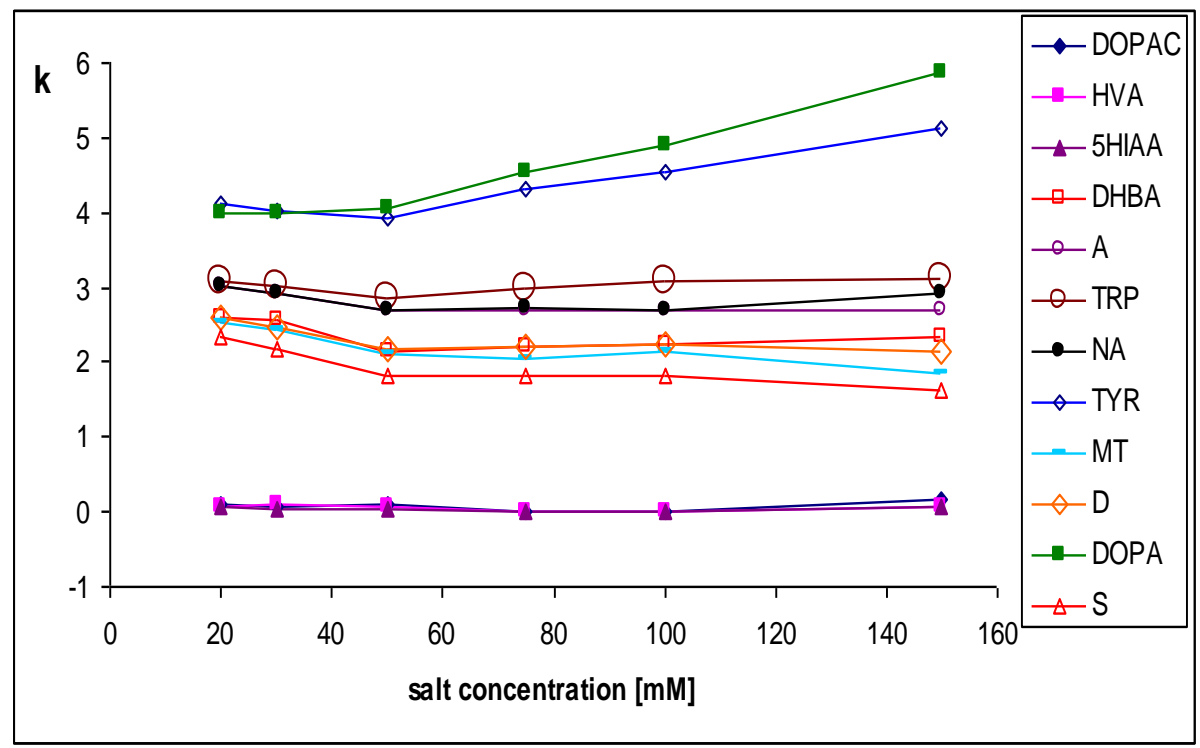

Fig. 2. Influence of the salt concentration on the retention factor.

In order to keep our mobile phase compatible with a MS detection the added salt needs to be volatile, under this conditions there are a limited number of salts that could be used to replace $\mathrm{HCOONH}_{4}$ [15]. Thus, the replacement of ammonium formate by ammonium acetate in the mobile phase didn't lead to better separation of the target compounds.

\subsection{The influence of $\mathrm{pH}$ on the retention factor}

In HILIC electrostatic interactions between the stationary phase and the charged or chargeable analytes can play a role in their retention [15]. The increase of the mobile phase $\mathrm{pH}$ leads to the deprotonation of the hydroxyl groups of the silica stationary phase that could offer new interactions possibilities for the analytes. More over the global charge of some analytes can also change and thus the exploration of the mobile phase $\mathrm{pH}$ influence on the retention seems appropriate. However, the $\mathrm{pH}$ influence, in the tested range (3-7), on retention factor for neutral and basic compounds is insignificant (data not shown). That is probably due to the fact that in the studied $\mathrm{pH}$ domain the global charge of these compounds does not undergo important variation. On the other hand, for the acid compounds (DOPAC, HVA, 5-HIAA) the charge differences are more important. One would expect that the acids, bearing a negative charge, would be less retained due to electrostatic repulsions with the negatively charged silica stationary phase. To our surprise, the retention factor for acid compounds increased 5 to 10 times with the $\mathrm{pH}$ increase (Figure 3). Never the less, the overall separation didn 't undergo significant improvement and taking into account the fact that the higher the $\mathrm{pH}$ the less stable the compounds are, we have decided to keep pH 3 for the used mobile phase.

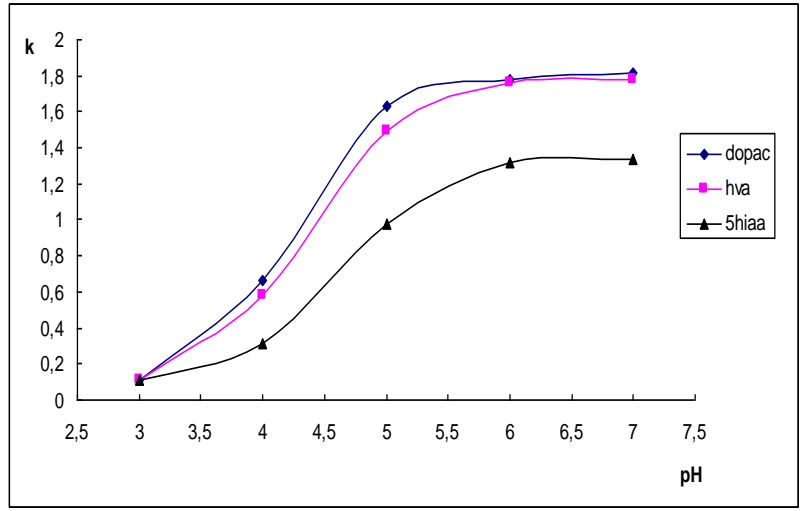

Fig. 3. $\mathrm{pH}$ influence on the retention factor for the acid compounds. 


\subsection{Influence of the temperature on retention factor}

From the literature we could observe that the temperature effect was function of the analytes nature and of the interaction between the analytes and the stationary phase [22]. In this case, the variation of the column temperature between 20 and $40{ }^{\circ} \mathrm{C}$ doesn't have significant influence on the retention factors of the analytes (Figure 4). The temperature increase doesn't lead to the separation improvement as retention decrease was observed for all solutes.

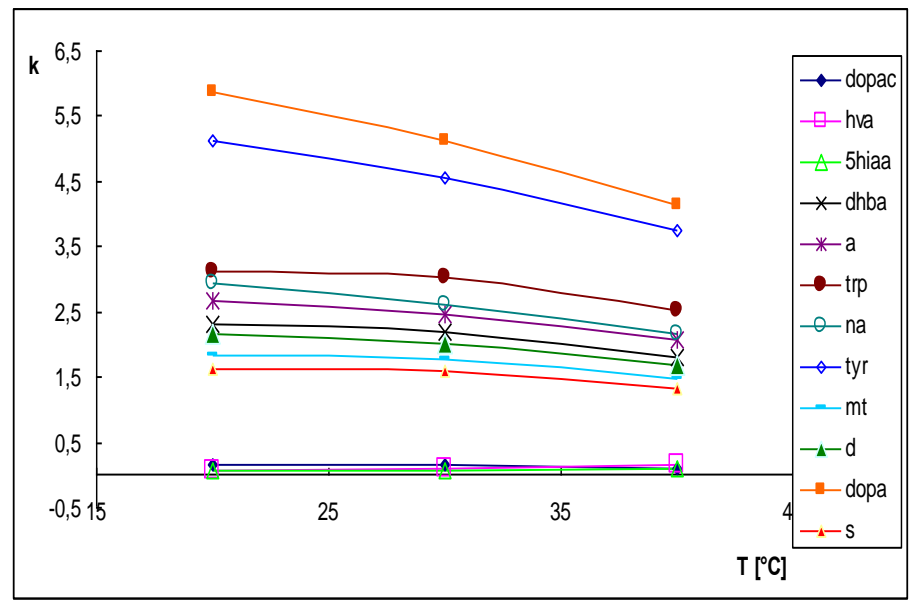

Fig. 4. $\mathrm{pH}$ influence on the retention factor.

\section{CONCLUSIONS}

The best analytes separation was obtained using a mobile phase composed of ACN and $\mathrm{HCOONH}_{4} 85: 15 \mathrm{v} / \mathrm{v}$, the aqueous part of the mobile phase has the $\mathrm{pH}$ equal to 3 (buffered by the addition of formic acid) and the salt concentration of $150 \mathrm{mM}$. The column temperature is $20^{\circ} \mathrm{C}$. Under these optimized conditions good separation between the 12 analytes was obtained (Figure 5). The first eluded compounds are far from the void volume allowing their quantification in complex matrices. The analysis time is reasonable (less than 25 minutes) and the peak shapes are correct (all peaks are symmetrical).

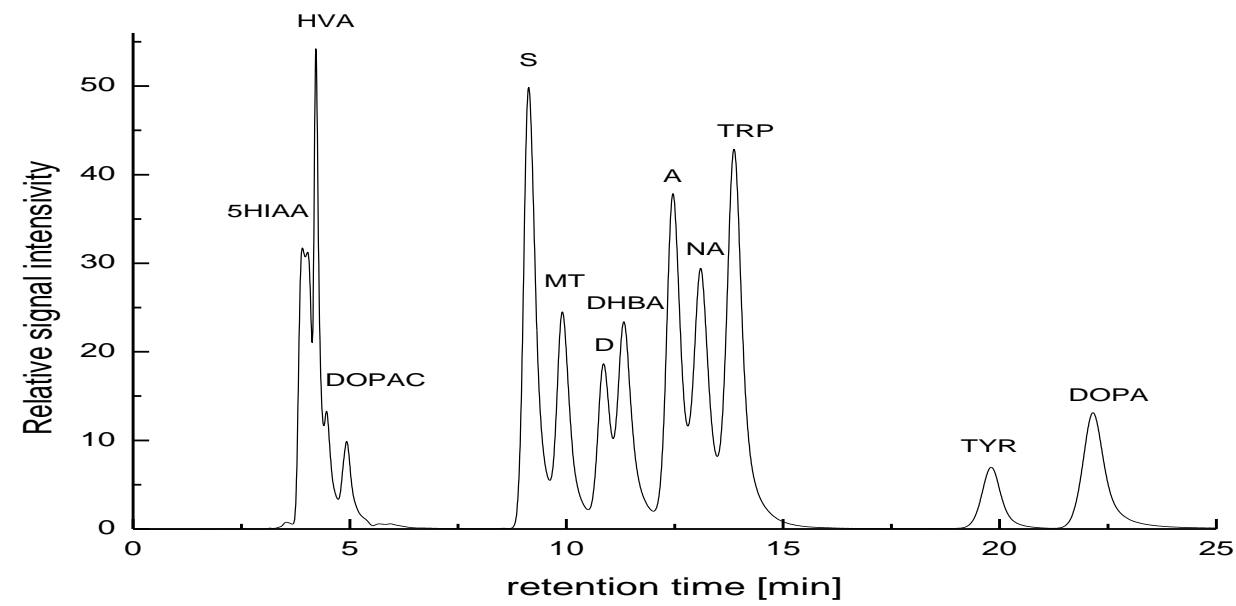

Fig. 5. Separation profile of 12 analytes under the optimized chromatographic conditions.

\section{REFERENCES}

[1] Von Bohlen und Halbach, O., Dermietzel, R., Neurotransmitters and neuromodulators - Handbook of receptors and biological effects, Ed. Willey-VCH, New Jersey, 2006. 
[2] Horn, F., Lindenmeier, G., Grillhosl, C., Moc, I., Berghold, S., Schneider, N., Munster, B., Biochimie humaine, Ed. Flammarion, 2005.

[3] Miki, K., Sudo, A., Effect of urine pH, Storage time, and temperature on stability of catecholamines, cortisol, and creatinine, Clinical Chemistry, vol. 44, no. 8, 1998, p. 1759-1762.

[4] Lagerstedt, S.A., O'Kane, D.J., Singh, R.J., Measurements of plasma free metanephrine and normetanephrine by liquid chromatography-tandem mass spectrometry for diagnosis of pheochromocytoma, Clinical Chemistry, vol. 50, no. 3, 2004, p. 603-611.

[5] Auber, F., Larroquet, M., Bonnard, A., Boudjemaa, S., Landman-Parker, J., Ducou Le Pointe, H., BocconGibod, L., Lefebvre, G., Uzan, S., Hélardot, P., Audry, G., Neuroblastomes de diagnostic échographique anténatal, Gynécologie Obstétrique \& Fertilité, vol. 33, no. 4, 2005, p. 228-231.

[6] Eisenhofer, G., Peitzsch, M., McWhinney, B.C., Impact of LC-MS/MS on the laboratory diagnosis of catecholamine-producing tumors, TrAC Trends in Analytical Chemistry, vol. 84 (Part B), 2016, p. 106-116.

[7] Ribeiro, J.A., Fernandes, P.M.V., Pereira, C.M., Silva, F., Electrochemical sensors and biosensors for determination of catecholamine neurotransmitters: A review, Talanta, vol. 160, 2016, p. 653-679.

[8] Koivisto, P., Tornkvist, A., Heldin, E., Markides, K.E., Separation of L-DOPA and four metabilites in plasma using a porous graphitic carbon column in capillary liquid chromatography, Chromatographia, vol. 55, 2002, p. $39-42$.

[9] Wood, A.T., Hall, M.R., Reversed-phase high-performance liquid chromatography ofcatecholamines and indoleamines using a simple gradient solvent system and native fluorescence detection, Journal of Chromatography B, vol. 744, no. 1, 2000, p. 221-225.

[10] Patel, B.A., Arundell, M., Parker, K.H., Yeoman, M.S., O'Hare, D., Simple and rapid determination of serotonin and catecholamines in biological tissue using high-performance liquid chromatography with electrochemical detection, Journal of Chromatography B, vol. 818, no. 2, 2005, p. 269-276.

[11] Lee, M., Oh, S.Y., Pathak, T.S., Paeng, I.R., Cho, B.Y., Paeng, K.J., Selective solid-phase extraction of catecholamines by the chemically modified polymeric adsorbents with crown ether, Journal of Chromatography A, vol. 1160, no. 1-2, 2007, p. 340-344.

[12] Thiébaut, D., Vial, J., Michel, M., Hennion, M.C., Greibrokk, T., Evaluation of reversed phase columns designed for polar compounds and porous graphitic carbon in "trapping" and separating neurotransmitters, Journal of Chromatography A, vol. 1122, no. 1-2, 2006, p. 97-104.

[13] Tampu, R.I., Patriciu, O.I., Elfakir, C., Catecholamines and related compounds separation on a mixed mode column, Scientific Study \& Research Chemistry \& Chemical Engineering, Biotechnology, Food Industry, vol. 15, no. 2, 2014, p.123-133.

[14] Kumar, A., Hart, J.P., McCalley, D.V., Determination of catecholamines in urine using hydrophilic interaction chromatography with electrochemical detection, Journal of Chromatography A, vol. 1218, no. 25, 2011 , p. 3854-3861.

[15] Chirita, R.I., West, C., Finaru, A.L., Elfakir, C., Approach to hydrophilic interaction chromatography column selection: Application to neurotransmitters analysis, Journal of Chromatography A, vol. 1217, no. 18, 2010, p. 3091-3104.

[16] Kanamori, T., Isokawa, M., Funatsu, T., Tsunoda, M., Development of analytical method for catechol compounds in mouse urine using hydrophilic interaction liquid chromatography with fluorescence detection, Journal of Chromatography B, vol. 985, 2015, p. 142-148.

[17] Alpert, A.J., Hydrophilic-interaction chromatography for the separation of peptides, nucleic acids and other polar compounds, Journal of Chromatography A, vol. 499, 1990, p. 177-196.

[18] Guo, Y., Gaiki, S., Retention behavior of small polar compounds on polar stationary phases in hydrophilic interaction chromatography, Journal of Chromatography A, vol. 1074, no. 1-2, 2005, p. 71-80.

[19] Yoshida, T., Peptide separation by hydrophilic-interaction chromatography: a review, Journal of Biochemical and Biophysical Methods, vol. 60, no. 3, 2004, p. 265-280.

[20] Hemstrom, P., Irgum, K., Hydrophilic interaction chromatography, Journal of Separation Science, vol. 29, 2006, p. 1784-1821.

[21] Chirita, R.I., Développement de nouvelles méthodes séparatives compatibles avec une détection par spectrométrie de masse et par électrochimie pour l'analyse des traces de catécholamines et molécules apparentées, $\mathrm{PhD}$ thesis, 2009.

[22] Hao, Z., Xiao, B., Weng, N., Impact of column temperature and mobile phase components on selectivity of hydrophilic interaction chromatography (HILIC), Journal of Separation Science, vol. 31, no. 9, 2008, p. 14491464. 